\title{
Dealcoholized red and white wines decrease oxidative stress associated with inflammation in rats
}

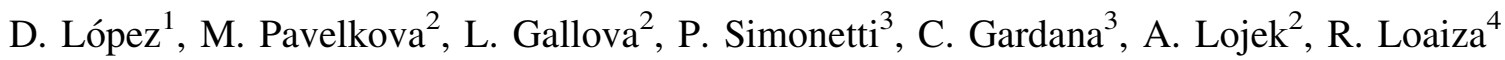 \\ and M. T. Mitjavila ${ }^{1} *$ \\ ${ }^{1}$ Department of Physiology, Faculty of Biology, University of Barcelona, Av. Diagonal 645, E-08028 Barcelona, Spain \\ ${ }^{2}$ Institute of Biophysics, Academy of Sciences, Královopolská 135, 61265 Brno, Czech Republic \\ ${ }^{3}$ Department of Food Science and Microbiology, University of Milano, Via Celoria 2, 20133 Milan, Italy \\ ${ }^{4}$ School of Pharmacy, University of Costa Rica, San Pedro de Montes de Oca, San José, Costa Rica
}

(Received 1 August 2006 - Revised 30 January 2007 - Accepted 20 February 2007)

\begin{abstract}
In vitro experiments have demonstrated that polyphenols exhibit antioxidant and anti-inflammatory activities. The present study was designed to test whether dealcoholized red (DRW) and white (DWW) wines can decrease the oxidative stress associated with inflammation in vivo. Rats were fed for $15 \mathrm{~d}$ either a control diet or one supplemented with DRW or DWW. Finally, a granuloma was induced by subcutaneous administration of carrageenan. Although DRW showed higher antioxidant activity in vitro than DWW, both wines decreased the number of cells recruited into the granuloma pouch. Malondialdehyde decreased in plasma and inflammatory exudate from rats fed with DRW- and DWW-rich diets. Moreover, the concentration of NO increased in exudate, which correlates with the increase in the citrulline:arginine ratio. Polymorphonuclear leucocytes from the inflammatory exudate of rats fed dealcoholized wines showed decreased superoxide anion $\left(\mathrm{O}_{2}^{--}\right)$production and increased $\mathrm{NO}$ production ex vivo. This change in NO production resulted from increased expression and activity of inducible NO synthase (EC 1.14.13.39). Moreover, the up regulation of cyclo-oxygenase-2 (EC 1.14.99.1) protein expression observed in rats fed the DRW-rich diet was not related to a direct effect of NO. The present results indicate that the non-alcoholic compounds of wines not only improve antioxidant status in an inflammatory situation, but also limit cell infiltration, possibly through a decrease in $\mathrm{O}_{2}^{--}$ and an increase in NO production.
\end{abstract}

Free radicals: Nitric oxide synthase: Polymorphonuclear leucocytes: Polyphenols

Most of the beneficial effects associated with the moderate consumption of red wine are related to polyphenols, although wines contain a broad range of non-polyphenolic compounds. In vitro studies have shown that polyphenols have antioxidant ${ }^{1-4}$ and anti-inflammatory activities. The anti-inflammatory activities are a consequence of the inhibition of phospholipase $\mathrm{A}_{2}$ (EC 3.1.1.4) ${ }^{5}$, cyclo-oxygenase (COX)- $2^{6}$ and 5-lipoxygenase ${ }^{7}$ (EC 1.13.11.34). However, evidence from the in vitro experiments cannot be extrapolated to in vivo settings, since polyphenols are extensively metabolized in vivo ${ }^{8-10}$, which can affect their activities.

The inflammatory response is characterized by the production of chemical mediators, and the presence of large amounts of exudate, proteins and cells in the inflamed area. Neutrophils are the first blood cells that migrate towards inflammatory lesions and they have the capacity to express NADPH oxidase, inducible NO synthase (iNOS) and COX-2. We have observed, in a carrageenan-induced granuloma model of inflammation, that polymorphonuclear $(\mathrm{PMN})$ leucocytes generate superoxide anion $\left(\mathrm{O}_{2}^{-}\right)$and
$\mathrm{NO}^{11}$ and it has been described that $\mathrm{O}_{2}^{--}$, by reacting with NO, generates peroxynitrite ${ }^{12,13}$. Thus, preventing the generation of $\mathrm{O}_{2}^{-}$by inhibiting the enzymes responsible or scavenging $\mathrm{O}_{2}^{--}$or avoiding peroxynitrite formation may attenuate inflammation.

It is likely that low levels of flavonoids and their metabolites exert biological effects such as altered cell signalling and gene expression that will contribute to the modulation of oxidative stress and inflammation. These activities have been more extensively studied in vitro than in vivo ${ }^{6,14}$. However, wine also contains alcohol that has been reported to enhance lipid peroxidation ${ }^{15}$ and can thus mask the effects of the non-alcoholic compounds. Our purpose was to explore the effects of dealcoholized red (DRW) and white (DWW) wines on rats with carrageenan-induced granulomas, because of the wines' absence of alcohol and also their differing polyphenol content. This model allowed us to examine the effects of both dealcoholized wines on oxidative stress and whether such effects would be beneficial in situations of inflammation.

Abbreviations: COX, cyclo-oxygenase; DRW, dealcoholized red wine; DWW, dealcoholized white wine; iNOS, inducible NO synthase; $\mathrm{O}_{2}^{--}$, superoxide anion; ORAC, oxygen radical absorbance capacity; PMN, polymorphonuclear.

* Corresponding author: Dr M. T. Mitjavila, fax +3493 4110358, email mmitjavila@ub.edu 


\section{Materials and methods}

\section{Animals and diets}

Male Sprague-Dawley rats weighing approximately $125 \mathrm{~g}$ were used (Harlan Interfauna Ibérica, Barcelona, Spain). They were housed in temperature-controlled rooms $\left(21-23^{\circ} \mathrm{C}\right)$, with $40-60 \%$ humidity, and exposed to a $12 \mathrm{~h}$ light-dark cycle.

Rats were randomly divided into three groups of seven rats and fed one of the following semi-purified diets for $15 \mathrm{~d}$ : (1) a control diet; (2) a $35 \%$ (v/w) DRW diet; or (3) a $35 \%$ (v/w) DWW diet (Table 1). Chow was prepared weekly ${ }^{16}$ and stored at $-20^{\circ} \mathrm{C}$ under vacuum to prevent oxidation and loss of antioxidants. Fresh food and water were provided in excess every day, and food consumption was recorded for every cage. All experimental protocols were reviewed and approved by the Ethical Committee of the University of Barcelona, in accordance with European Community guidelines.

Dealcoholized wines were prepared from common commercial wines available in Spain. Alcohol was removed using a rotary evaporator at a maximum temperature of $30^{\circ} \mathrm{C}$. Vacuum was applied progressively to avoid mechanical stress. Evaporated ethanol was replaced by acidulated distilled water and the $\mathrm{pH}$ was adjusted to that of the original wine. GC was used to identify any traces of ethanol in dealcoholized wines. We have also evaluated the ascorbic acid and fructose content in wines by fluorimetric ${ }^{17}$ and colorimetric techniques (Boehringer Mannheim, Darmstadt, Germany), respectively.

\section{Liquid chromatography-mass spectrometry analysis, total phenol content and antioxidant activity of wines}

Wines were diluted in methanol-formic acid $1 \%(90: 10, \mathrm{v} / \mathrm{v})$ and the resulting solutions were sonicated for $10 \mathrm{~min}$ and centrifuged at $1000 \mathrm{~g}$ for $10 \mathrm{~min}$. One sample of the supernatant fraction was filtered through a Millipore $0.2 \mu \mathrm{m}$ disk and $20 \mu \mathrm{l}$ was used for analysis.

The chromatographic system for liquid chromatographyMS analysis of wines ${ }^{18}$ included an Alliance model 2695 (Waters, Milford, MA, USA) coupled with a diode array

Table 1. Composition of semi-purified diets $(\mathrm{g} / \mathrm{kg})^{*}$

\begin{tabular}{lrrr}
\hline & \multicolumn{3}{c}{ Diet } \\
\cline { 2 - 4 } Component & Control & DRW & DWW \\
\hline Casein & 225 & 225 & 225 \\
Potato starch & 446 & 446 & 446 \\
Sucrose & 223 & 223 & 223 \\
Cellulose & 31 & 31 & 31 \\
dl-Methionine & 1 & 1 & 1 \\
Mineral mix $†$ & 14 & 14 & 14 \\
Vitamin mix $\ddagger$ & 10 & 10 & 10 \\
Maize oil & 50 & 50 & 40 \\
Water & 350 & 0 & 0 \\
Wine & 0 & 350 & 350 \\
\hline
\end{tabular}

DRW, dealcoholized red wine; DWW, dealcoholized white wine.

* Pellets were dried at room temperature for $12 \mathrm{~h}$. † AIN-93M-MX (ICN Pharmaceuticals, Costa Mesa, CA, USA). $\ddagger$ AIN-93VX (ICN Pharmaceuticals). detector (model 2996; Waters) and a triple-quadrupole mass spectrometer (model Quattro micro; Micromass, Beverly, MA, USA). The analytical column was a $3.5 \mu \mathrm{m} \mathrm{C}_{18}$ Symmetry $150 \times 2.1 \mathrm{~mm}$ (Waters). The column was maintained at $30^{\circ} \mathrm{C}$. The mobile phase consisted of water (solvent $\mathrm{A}$ ) and acetonitrile (solvent B), both with $0.1 \%$ formic acid. The flow rate was set at $200 \mu \mathrm{l} / \mathrm{min}$. The separation was carried out with a linear solvent gradient program starting at $0 \% \mathrm{~B}$ and ramping to $20 \% \mathrm{~B}$ in $30 \mathrm{~min}$ and to $60 \%$ in $10 \mathrm{~min}$. The mass spectrometer was equipped with an electrospray source operating both in the positive (anthocyanin analysis) and negative (polyphenols) ion mode. The capillary voltage was set to $3.2 \mathrm{kV}$, the sampling cone voltage to $40 \mathrm{~V}$, and the source temperature to $130^{\circ} \mathrm{C}$. The analysis was carried out in full scan mode in the range 100-1000 atomic mass units, while UV-Vis chromatograms were acquired in the range $200-600 \mathrm{~nm}$. All data were acquired by Masslink 4.0 software (Micromass).

Anthocyanin calibration curves were obtained from stock solutions prepared by dissolving $5 \mathrm{mg}$ standard powder (Extrasynthese, Genay, France) in $5 \mathrm{ml}$ methanol-formic acid $10 \%$ (90:10, v/v). Gallic, $p$-coumaric, ferulic and caffeic acid, catechin, epicatechin, trans-resveratrol (Sigma, St Louis, MO, USA), myricetin, quercetin (Extrasynthese) and stock solutions were prepared by dissolving $20 \mathrm{mg}$ standard powder in $20 \mathrm{ml}$ methanol. The working solutions were prepared in the range $1-50 \mu \mathrm{g} / \mathrm{ml}$.

Total phenols in dealcoholized wines were measured following the Folin-Ciocalteau colorimetric method, and utilizing gallic acid as a standard ${ }^{19}$.

The antioxidant potential of dealcoholized wines was determined by using four methods. The reducing power was determined in $150 \mu \mathrm{l}$ according to the method described by Oyaizu $^{20}$, using quercetin as a standard. The oxygen radical absorbance capacity (ORAC) assay was used to elucidate the antioxidant behaviour of dealcoholized wines (dilutions $1: 25, \mathrm{v} / \mathrm{v}$ ) against the peroxyl radicals by using $R$-phycoerythrin as a redox-sensitive fluorescent indicator and $2,2^{\prime}$,azobis-(2-amidinopropane) dihydrochloride as a chemical peroxyl radical generator ${ }^{21}$. $R$-phycoerythrin fluorescence decline was measured at $37^{\circ} \mathrm{C}$ as the difference between 5 and $30 \mathrm{~min}$ (excitation wavelength $530 \mathrm{~nm}$, emission wavelength $585 \mathrm{~nm}$ ). The $\mathrm{O}_{2}^{--}$-scavenging activity was quantified in serial dilution of wines using the hypoxanthine-xanthine oxidase (EC 1.17.3.2) system, whereby the reduction rate of nitroblue tetrazolium to a dark-blue formazan is measured at $540 \mathrm{~nm}$ every $1 \mathrm{~min}$ for a $20 \mathrm{~min}$ period $^{22}$. Maximal velocity was computed to determine the necessary concentration for inducing a $50 \%$ scavenging of the $\mathrm{O}_{2}^{--}$produced. NO scavenging was determined according to the method described by Vriesman et $a .^{23}$ with some modifications. Briefly, NO was chemically generated by dilution of $50 \mu 150 \mathrm{mM}-\mathrm{NaNO}_{2}$ (giving $250 \mathrm{nmol} \mathrm{NO} / \mathrm{l}$ ) in $10 \mathrm{ml} 0 \cdot 1 \mathrm{M}-\mathrm{H}_{2} \mathrm{SO}_{4}$ and $0 \cdot 1 \mathrm{M}-\mathrm{KI}$ (pH 1.0). After $2 \mathrm{~min}$, DRW and DWW were added to a final concentration of $1: 100$ to $1: 1000$, with $\mathrm{Hb}$ used as the standard. During measurement, the test vial was kept under a stream of $\mathrm{N}_{2}$. NO concentration was monitored using an Iso-NOP NO sensor (World Precision Instruments, Saratosa, FL, USA). The natural logarithm of the electrode values was plotted $v$. time and the (pseudo) first-order reaction constant for scavenging was calculated. 


\section{Induction of inflammation and evaluation of inflammatory parameters}

After day 15 of the experimental feeding period, a granuloma was induced by subcutaneous administration of $6 \mathrm{ml}$ air, followed $24 \mathrm{~h}$ later by $4 \mathrm{ml}$ carrageenan (Hispanoland, Barcelona, Spain) $2 \%(\mathrm{w} / \mathrm{v})$ in sterile saline, into the dorsum of rats as previously described ${ }^{24}$. Rats were anaesthetized with isofluorane (Abbott Laboratories, Madrid, Spain) $24 \mathrm{~h}$ after carrageenan injection. Blood, extracted by heart puncture, and the inflammatory pouch exudates were harvested following overnight fast using heparin-treated syringes. The pouch cavity was then rinsed with $3 \mathrm{ml}$ saline to recover all cells and the granulomatous tissue extracted and weighed. Blood and exudates were centrifuged at $800 \mathrm{~g}$ and the exudates obtained in the presence of EDTA were filtered through Millipore $10 \mathrm{kDa}$ filters (Millipore, Bedford, MA, USA). After hypo-osmotic lysis of contaminating erythrocytes, PMN cells were re-suspended in PBS (pH 7.4) without $\mathrm{Ca}^{2+}$ or $\mathrm{Mg}^{2+}$, washed twice and re-suspended in the same buffer with $2 \mathrm{mM}-\mathrm{Ca}^{2+}$ and $0.5 \mathrm{mM}-\mathrm{Mg}^{2+}$ and counted ${ }^{11}$. Samples of plasma and exudates were flushed with $\mathrm{N}_{2}$ and stored at $-80^{\circ} \mathrm{C}$.

The osmolarity and protein concentration were evaluated in the supernatant fraction of the exudates using a micro-osmometer (Advanced Instruments, Needham Heights, MA, USA) and the Biuret method, respectively. For $\mathrm{PGE}_{2}$ measurement, $50 \mu \mathrm{l}$ supernatant fraction of the exudates were processed through $\mathrm{C}_{18}$ solid-phase Sep-Pack cartridges (Waters), previously activated with methanol and acidified water $(\mathrm{pH} \mathrm{4.0)}$. Eluates from $5 \mathrm{ml}$ methanol were evaporated under $\mathrm{N}_{2}$, and the resulting dried residues were re-suspended for $\mathrm{PGE}_{2}$ immunoassay analysis (Cayman Chemicals, Ann Arbor, MI, USA).

\section{Parameters related to oxidative stress in plasma and supernatant fraction of the exudates}

We measured the total phenol and the antioxidant potential, both in plasma and exudate supernatant fractions. For antioxidant potential, we used three methods described elsewhere.

Malondialdehyde was assayed as an endproduct of lipid peroxidation. Malondialdehyde equivalents were measured in $200 \mu \mathrm{l}$ samples using the thiobarbituric acid-reactive substances method, with tetraethoxypropane as a standard ${ }^{25}$. Thiobarbituric acid-reactive substances were extracted with butanol. The tubes were centrifuged at $450 \mathrm{~g}$ for $10 \mathrm{~min}$ and the absorbance of the upper phase was measured at $540 \mathrm{~nm}$.

NO released in plasma or in exudate supernatant fractions is oxidized to nitrites. NO was thus measured in deproteinized samples $(100 \mu \mathrm{l})$ by $20 \% \mathrm{TCA}(1: 1)$ at $4^{\circ} \mathrm{C}$ and centrifuged at $18600 \mathrm{~g}$ for $15 \mathrm{~min}$. Supernatant fractions $(50 \mu \mathrm{l})$ were incubated in $5 \mathrm{ml}$ of a solution $\left(10 \mathrm{mM}-\mathrm{KI}, 10 \mathrm{mM}-\mathrm{H}_{2} \mathrm{SO}_{4}\right)$ converting nitrites to $\mathrm{NO}$, which was evaluated by the $2.0 \mathrm{~mm}$ NO sensor (ISO-NOP). The maximal signal was recorded and compared with a $\mathrm{NaNO}_{2}$ standard.

The relationship between free L-citrulline $v$. free L-arginine was also measured in deproteinized and ultramicrofiltrated exudate supernatant fractions. Amino acid analysis was conducted by cation-exchange chromatography coupled to an auto-analyser (Alpha Plus; Pharmacia LKB Biotechnology $\mathrm{AB}$, Uppsala, Sweden) according to the method of Moore et $a .^{26}$ with post-column derivatisation with ninhydrin.
Lithium citrate buffers were used as eluents. Identification and quantification of amino acids was performed according to the retention time and peak areas, respectively, of standards eluted in the same conditions. Norleucine was used as an internal standard. The detection limit was $1 \mathrm{nmol}$.

Free radical production by polymorphonuclear leucocytes and inducible nitric oxide synthase and cyclo-oxygenase-2 assays

Cells isolated from inflammatory exudates were used to measure $\mathrm{O}_{2}^{--}$and NO production as previously described ${ }^{11}$. The viability of the cells was above $90 \%$, as assessed by the Trypan blue exclusion test, and $85-90 \%$ of the cells were PMN cells. Less than $1 \mathrm{~h}$ elapsed between harvesting the exudates and the start of incubation. PMN cells $\left(1 \times 10^{6}\right.$ cells per tube) were incubated for $1 \mathrm{~h}$ in $\mathrm{PBS}$, at a $\mathrm{pH}$ of 7.4 with $2 \mathrm{mM}^{-\mathrm{CaCl}_{2}}, 0.5 \mathrm{mM}-\mathrm{MgCl}_{2}$, and phorbol 12-myristate 13 -acetate $(100 \mu \mathrm{g} / \mathrm{l})$.

$\mathrm{O}_{2}^{--}$generation was assayed by measuring superoxide dismutase (EC 1.15.1.1)-inhibitable reduction of cytochrome c $(0.15 \mathrm{~mm}$; horse heart type VI) in the presence of $N$-iminoethyl-L-ornithine (0.6 mM; Sigma), an NOS inhibitor.

Nitrites plus nitrates were measured as indicators of NO generation by PMN cells, and assays were performed in the presence of L-arginine $(0.6 \mathrm{~mm})$ and 150 international units superoxide dismutase. In addition, $N$-imino-ethyl-L-ornithine $(0.6 \mathrm{~mm})$ was used as a negative control for each experiment. Incubation medium $(60 \mu \mathrm{l})$ was treated with $10 \mu \mathrm{l}$ nitrate reductase (EC 1.7.1.3) (Cayman Chemicals) followed by Griess reagent.

To evaluate iNOS protein expression (Immun-Star AntiRabbit Detection kit; Cayman Chemicals), $10^{7}$ PMN cells were incubated in $500 \mu \mathrm{l}$ lysis buffer containing $50 \mathrm{~mm}$-tri (hydroxymethyl)-aminomethane- $\mathrm{HCl} \quad(\mathrm{pH} \quad 7 \cdot 4), \quad 500 \mu \mathrm{M}-$ EDTA, $500 \mu \mathrm{M}$-ethylene-glycol-bis(2-aminoethyl ether)- $N, N$, $N^{\prime}, N^{\prime}$-tetra-acetic acid, $7 \mathrm{~mm}$-glutathione, $10 \%$ glycerol (v/v), 20 mM-3-[(3-cholamidopropyl)dimethylammonio]-2-hydroxy1-propanesulfonate, $100 \mathrm{~mm}$-dithiothreitol, pepstatin $(1 \mu \mathrm{g} / \mathrm{ml})$, aprotinin $(1 \mu \mathrm{g} / \mathrm{ml})$, leupeptin $(1 \mu \mathrm{g} / \mathrm{ml})$ and $2 \mathrm{~mm}$-phenylmethylsulfonyl fluoride for $30 \mathrm{~min}$ at $4^{\circ} \mathrm{C}$. Samples were sonicated and boiled at $95^{\circ} \mathrm{C}$ for $3 \mathrm{~min}$. Protein concentration was determined using the Bradford technique. Homogenate samples ( $20 \mu \mathrm{g}$ protein per lane) were submitted to gel electrophoresis and blotted onto a nitrocellulose membrane. Purified murine iNOS (Cayman Chemicals) was also loaded ( $1 \mu \mathrm{g})$ as a positive control, and a pre-stained protein standard was used to monitor transfer efficiency. Membranes were then exposed to a 1:1000 ratio of rabbit anti-human iNOS polyclonal antibody (Cayman Chemicals) and a 1:1000 ratio of rabbit anti-chicken polyclonal $\gamma$-tubulin (Sigma) as housekeeping for $1 \mathrm{~h}$. The relative densitometric units with regard to murine iNOS were evaluated.

PMN iNOS activity in rats fed the different diets was measured by quantifying the amount of $\left[{ }^{3} \mathrm{H}\right] \mathrm{L}$-citrulline formed from $\left[{ }^{3} \mathrm{H}\right] \mathrm{L}$-arginine in $10^{7}$ cells. $\left[{ }^{3} \mathrm{H}\right] \mathrm{L}$-citrulline content (Cayman Chemicals) was measured by liquid scintillation counting using a Packard Top-Count instrument (Packard Instrument Company, Meriden, CT, USA). To selectively measure iNOS, a $\mathrm{Ca}^{2+}$-free buffer was used with ethyleneglycol-bis(2-aminoethyl ether)- $N, N, N^{\prime}, N^{\prime}$-tetra-acetic acid present in a final concentration of $1 \mathrm{~mm}$. Non-enzymic conversion 
was determined by using a heat-inactivated $\left(2 \mathrm{~min}\right.$ at $\left.100^{\circ} \mathrm{C}\right)$ cell suspension containing $10^{7}$ cells. As a negative control for each experiment, $1 \mathrm{mM}-N^{\mathrm{G}}$-nitro-L-arginine methyl ester-HCl (Sigma), an inhibitor of NOS, was added to the incubation medium for $30 \mathrm{~min}$.

To evaluate COX-2 protein expression, $10^{7} \mathrm{PMN}$ cells were incubated in $500 \mu \mathrm{l}$ of the lysis buffer used for iNOS protein expression for $30 \mathrm{~min}$ at $4^{\circ} \mathrm{C}$. Samples were treated as for iNOS expression. In addition, purified murine COX-2 was loaded $(2 \mu \mathrm{g})$ as a positive control and a pre-stained protein standard was used to monitor electrophoresis and transfer efficiency. Membranes were then exposed to a 1:2000 ratio of rabbit anti-murine COX-2 polyclonal antibody (Sigma) and a 1:1000 ratio of rabbit anti-chicken $\gamma$-tubulin polyclonal antibody for $1 \mathrm{~h}$ and then processed as for iNOS expression.

COX-2 activity in PMN cells was measured by quantifying the amount of $\mathrm{PGE}_{2}$ that can be formed from arachidonic acid (Cayman Chemicals). Cells $\left(10^{7}\right)$ were incubated in $500 \mu \mathrm{l}$ buffer $(\mathrm{pH} 7.4)$ containing $0.14 \mathrm{M}-\mathrm{NaCl}, 1.59 \mathrm{~mm}-$ $\mathrm{NaH}_{2} \mathrm{PO}_{4} .2 \mathrm{H}_{2} \mathrm{O}, \quad 8.8 \mathrm{~mm}-\mathrm{Na}_{2} \mathrm{HPO}_{4} .2 \mathrm{H}_{2} \mathrm{O}, \quad 2 \mathrm{~mm}$-EDTA, $100 \mathrm{~mm}$-dithiothreitol, leupeptin $(1 \mu \mathrm{g} / \mathrm{ml})$, aprotinin $(1 \mu \mathrm{g} /$ $\mathrm{ml}$ ) and $2 \mathrm{~mm}$-phenylmethylsulfonyl fluoride for $30 \mathrm{~min}$ at $4^{\circ} \mathrm{C}$. Samples were sonicated and boiled at $95^{\circ} \mathrm{C}$ for $3 \mathrm{~min}$. After centrifugation at $14000 \mathrm{~g}$ for $10 \mathrm{~min}$, protein concentration was evaluated in homogenates. Homogenate samples $(10 \mu \mathrm{l})$ were incubated in $1 \mathrm{ml} 0 \cdot 1 \mathrm{M}$-tri(hydroxymethyl)-aminomethane- $\mathrm{HCl}$ (pH 8.0), 5 mM-EDTA and $2 \mathrm{~mm}$-phenol, in the presence of haeme group and arachidonic acid. A COXinhibitor, indomethacin $(10 \mathrm{mM})$, was added for sample control. After $2 \mathrm{~min}$ of incubation at $37^{\circ} \mathrm{C}$, the reaction was stopped with $50 \mu \mathrm{HCl}$.

\section{Statistical methods}

Statistical analysis of the data was performed using SPSS software, version 11.5 (SPSS Inc., Chicago, IL, USA). The results are expressed as mean values with their standard errors. Data were evaluated using either the unpaired Student's $t$ test or one-way ANOVA. Homogeneity of variances was tested by the Bartlett's test. The Student-Newman-Keuls multiple comparison test was used to detect differences among groups $(P<0 \cdot 05)$. Correlations between variables were studied by linear regression.

\section{Results}

\section{Dealcoholized wines and diets}

According to GC, the ethanol content of DRW and DWW was less than $3 \mathrm{~g} / \mathrm{l}$. Red wine had a higher concentration of polyphenolic compounds than white (Table 2). The dealcoholization process did not alter the polyphenolic composition of wines. The total polyphenol content was also higher in DRW than in DWW (8.64 and $1.82 \mathrm{~mm}$ gallic acid equivalents/M, respectively; $P<0.001$ ) (Table 3 ).

The antioxidant activities in vitro were lower in DWW than in DRW (Table 3). Hypoxanthine-xanthine oxidase and ORAC were better correlated with total phenol $(r 0.9378$ and $r 0.9577$, respectively; $P<0.01)$ than with the reducing power $(r 0.9015$ and $r 0.9011$, respectively; $P<0.05)$. The largest difference observed between the two wines was the
Table 2. Phenolic compounds in wines $(\mathrm{mg} / \mathrm{l})^{*}$

(Mean values with their standard errors for two replicates from three bottles of wine)

\begin{tabular}{|c|c|c|c|c|}
\hline \multirow[b]{2}{*}{ Compound } & \multicolumn{2}{|c|}{ Red wine } & \multicolumn{2}{|c|}{ White wine } \\
\hline & Mean & SE & Mean & SE \\
\hline \multicolumn{5}{|l|}{ Phenolic acids } \\
\hline Gallic acid & $26 \cdot 7$ & 0.30 & $3 \cdot 2$ & 0.03 \\
\hline$p$-Coumaric acid & $6 \cdot 7$ & 0.05 & 0.8 & 0.04 \\
\hline Caffeic acid & 2.5 & 0.02 & 0.4 & 0.01 \\
\hline Other phenolic acids & 54.0 & 0.40 & 4.9 & 0.06 \\
\hline \multicolumn{5}{|l|}{ Flavanols } \\
\hline Catechin & 29.8 & 0.10 & 5.3 & 0.12 \\
\hline Epicatechin & $17 \cdot 7$ & 0.20 & 1.9 & 0.06 \\
\hline \multicolumn{5}{|l|}{ Flavonols } \\
\hline Myricetin & 1.8 & 0.03 & ND & \\
\hline Quercetin & 51.4 & 0.06 & ND & \\
\hline Kaempferol & 1.8 & 0.10 & ND & \\
\hline Myricentin glucoside & 3.7 & 0.02 & - & \\
\hline Quercetin glucoside & 1.5 & 0.01 & - & \\
\hline Isorhamnetin glucoside & $5 \cdot 8$ & 0.06 & - & \\
\hline \multicolumn{5}{|l|}{ Anthocyanins } \\
\hline Pelargonidin-3-glucoside & 3.7 & 0.02 & - & \\
\hline Cyanidin-3-glucoside & 0.5 & 0.01 & - & \\
\hline Petunidin-3-glucoside & $4 \cdot 3$ & 0.04 & - & \\
\hline Peonidin-3-glucoside & $6 \cdot 1$ & 0.07 & - & \\
\hline Malvidin-3-glucoside & 29.1 & 0.15 & - & \\
\hline Cyanidin-3-glucoside-malonyl & 1.4 & 0.00 & - & \\
\hline $\begin{array}{l}\text { Peonidin-3-glucoside- } p \text {-coumaroyl } \\
\text { malvidin-3-glucoside- } p \text {-coumaroyl }\end{array}$ & $+2 \cdot 1$ & 0.00 & - & \\
\hline Trans-resveratrol & 3.6 & 0.11 & ND & \\
\hline
\end{tabular}

ND, not detected.

${ }^{\star}$ For details of diets and procedures, see Table 1 and Materials and methods.

12-fold higher NO scavenging activity of DRW (2.72 mmol $\mathrm{Hb}$ equivalents/l) v. DWW $(0.23 \mathrm{mmol} \mathrm{Hb}$ equivalents $/ \mathrm{M})$ $(P<0 \cdot 001)$ (Table 3).

Ascorbic acid and fructose content in both dealcoholized wines was of the order of $6 \mu \mathrm{M}$ and $0.25 \mathrm{~g} / \mathrm{l}$. According to the wine maker the concentration of sulfites was 110 and $120 \mathrm{mg} / \mathrm{l}$ for the red and white wine, respectively. Feeding rats a wine-rich diet for $15 \mathrm{~d}$ had no effect on food or water ingestion, and the body-weight gain in the treated groups was similar to the control group.

\section{Inflammatory parameters in exudates}

There were no significant differences in the weight of granuloma between dietary groups. Similar volumes of exudate, osmolarity and protein concentration in supernatant fractions of the exudates were observed in the three groups of rats. However, the number of cells in inflammatory exudates decreased by about $47 \%$ in both groups of treated rats. $\mathrm{PGE}_{2}$ concentration increased in exudates from DRW-fed rats (Table 4).

\section{Biomarkers of oxidative stress in plasma and supernatant fraction of exudates}

Reducing power, ORAC activities and $\mathrm{O}_{2}^{--}$were higher in plasma than in exudate supernatant fractions (Table 5). However, the DRW diet significantly increased ORAC $(23 \%)$ and the $\mathrm{O}_{2}^{--}$scavenging activity (50\% scavenging 
Table 3. Total phenols and antioxidant activities of dealcoholized wines $†$

(Mean values with their standard errors for two replicates from three bottles of dealcoholized wine)

\begin{tabular}{|c|c|c|c|c|}
\hline & \multicolumn{2}{|c|}{ DRW } & \multicolumn{2}{|c|}{ DWW } \\
\hline & Mean & SE & Mean & SE \\
\hline Total phenols ( $\mathrm{mm}$ gallic acid equivalents/M) & 8.64 & 0.06 & $1.82^{*}$ & 0.05 \\
\hline Reducing power (mM quercetin equivalents/M) & 4.88 & 0.25 & $1 \cdot 26^{*}$ & 0.07 \\
\hline Hypoxanthine-xanthine oxidase $\mathrm{SC}_{50}(\mu \mathrm{l} / \mathrm{ml})$ & $17 \cdot 00$ & $2 \cdot 00$ & $32 \cdot 00^{*}$ & 2.00 \\
\hline ORAC (mM trolox equivalents/M) & $3 \cdot 10$ & $0 \cdot 10$ & $2 \cdot 20^{*}$ & $0 \cdot 10$ \\
\hline NO scavenging ( $\mathrm{mm} \mathrm{Hb}$ equivalents/M) & 2.72 & 0.06 & $0.23^{*}$ & 0.02 \\
\hline
\end{tabular}

DRW, dealcoholized red wine; DWW, dealcoholized white wine; $\mathrm{SC}_{50}, 50 \%$ scavenging concentration; ORAC, oxygen radical absorbance capacity.

* Mean value was significantly different from that of DRW $(P<0.001$; Student's unpaired $t$ test $)$

$\dagger$ For details of diets and procedures, see Table 1 and Materials and methods.

Table 4. Body weight, exudate parameters and granuloma weight after $24 \mathrm{~h}$ of carrageenan granuloma induction* (Mean values with their standard errors for two replicates from seven rats)

\begin{tabular}{|c|c|c|c|c|c|c|}
\hline & \multicolumn{2}{|c|}{ Control } & \multicolumn{2}{|c|}{ DRW } & \multicolumn{2}{|c|}{ DWW } \\
\hline & Mean & SE & Mean & SE & Mean & SE \\
\hline Body weight (g) & $222 \cdot 0^{\mathrm{a}}$ & $15 \cdot 0$ & $207 \cdot 0^{\mathrm{a}}$ & $13 \cdot 0$ & $217 \cdot 0^{\mathrm{a}}$ & $14 \cdot 0$ \\
\hline Weight of granuloma $(\mathrm{g})$ & $6 \cdot 3^{\mathrm{a}}$ & 1.4 & $4 \cdot 0^{\mathrm{a}}$ & 0.7 & $5 \cdot 6^{\mathrm{a}}$ & 1.0 \\
\hline Volume of exudates (ml) & $4 \cdot 3^{\mathrm{a}}$ & 0.8 & $4 \cdot 9^{\mathrm{a}}$ & 0.5 & $3 \cdot 9^{\mathrm{a}}$ & 0.6 \\
\hline Osmolarity of exudate (mOsmol/l) & $303 \cdot 0^{\mathrm{a}}$ & 1.0 & $300 \cdot 0^{\mathrm{a}}$ & 3.0 & $302 \cdot 0^{\mathrm{a}}$ & $2 \cdot 0$ \\
\hline Protein concentration in exudate supernatant fractions $(\mathrm{g} / \mathrm{l})$ & $1.5^{\mathrm{a}}$ & $0 \cdot 1$ & $1.5^{\mathrm{a}}$ & 0.1 & $1.6^{\mathrm{a}}$ & 0.1 \\
\hline Number of cells in exudate $\left(\times 10^{6}\right)$ & $95 \cdot 0^{\mathrm{b}}$ & $7 \cdot 0$ & $50 \cdot 0^{\mathrm{a}}$ & $6 \cdot 0$ & $51 \cdot 0^{\mathrm{a}}$ & 4.0 \\
\hline $\mathrm{PGE}_{2}$ in exudate supernatant fractions $(\mathrm{pg} / \mathrm{ml}) \dagger$ & $66 \cdot 0^{\mathrm{a}}$ & $4 \cdot 0$ & $82 \cdot 0^{\mathrm{b}}$ & $4 \cdot 0$ & $74 \cdot 0^{\mathrm{a}}$ & $5 \cdot 0$ \\
\hline
\end{tabular}

DRW, dealcoholized red wine; DWW, dealcoholized white wine.

${ }_{a, b}$ Mean values within a row with unlike superscript letters were significantly different $(P<0.05)$.

${ }^{*}$ For details of diets and procedures, see Table 1 and Materials and methods.

†Two replicates from seven rats.

Table 5. Oxidative stress in plasma and supernatant fraction of exudates after $24 \mathrm{~h}$ of carrageenan granuloma induction* (Mean values with their standard errors for two replicates from seven rats)

\begin{tabular}{|c|c|c|c|c|c|c|c|c|c|c|c|c|}
\hline & \multicolumn{6}{|c|}{ Plasma } & \multicolumn{6}{|c|}{ Supernatant fraction of exudates } \\
\hline & \multicolumn{2}{|c|}{ Control } & \multicolumn{2}{|l|}{ DRW } & \multicolumn{2}{|c|}{ DWW } & \multicolumn{2}{|c|}{ Control } & \multicolumn{2}{|c|}{ DRW } & \multicolumn{2}{|c|}{ DWW } \\
\hline & Mean & SE & Mean & SE & Mean & SE & Mean & SE & Mean & SE & Mean & SE \\
\hline $\begin{array}{l}\text { Total phenols } \\
\text { (nM gallic acid equivalents/M) }\end{array}$ & $950^{\mathrm{a}}$ & 60 & $1130^{b}$ & 30 & $1080^{b}$ & 40 & $80^{\mathrm{a}}$ & 30 & $91^{\mathrm{b}}$ & 60 & $83^{a}$ & 40 \\
\hline $\begin{array}{l}\text { Reducing power } \\
\quad(\mu \mathrm{M} \text { quercetin equivalents/M) }\end{array}$ & $111 \cdot 0^{\mathrm{a}}$ & $8 \cdot 0$ & $134 \cdot 0^{\mathrm{ab}}$ & $11 \cdot 0$ & $147 \cdot 0^{\mathrm{b}}$ & $11 \cdot 0$ & $54 \cdot 0^{a}$ & $4 \cdot 0$ & $76 \cdot 0^{\mathrm{b}}$ & $4 \cdot 0$ & $76 \cdot 0^{b}$ & $5 \cdot 0$ \\
\hline $\begin{array}{l}\mathrm{O}_{2}^{--} \text {scavenging } \\
\text { (hypoxanthine-xanthine } \\
\left.\text { oxidase } \mathrm{SC}_{50}\right)(\mu \mathrm{l} / \mathrm{ml})\end{array}$ & $45 \cdot 0^{\mathrm{C}}$ & $2 \cdot 0$ & $26 \cdot 0^{\mathrm{a}}$ & 1.0 & $39.0^{\mathrm{b}}$ & $2 \cdot 0$ & $96 \cdot 0^{\mathrm{b}}$ & $9 \cdot 0$ & $70 \cdot 0^{\mathrm{a}}$ & $5 \cdot 0$ & $73 \cdot 0^{a}$ & $4 \cdot 0$ \\
\hline $\begin{array}{l}\text { ORAC } \\
(\mathrm{mM} \text { trolox equivalents/M) }\end{array}$ & $2 \cdot 2^{\mathrm{a}}$ & 0.1 & $2 \cdot 7^{\mathrm{b}}$ & 0.1 & $2 \cdot 7^{\mathrm{b}}$ & 0.1 & $1.4^{\mathrm{a}}$ & 0.1 & $2 \cdot 7^{\mathrm{b}}$ & 0.1 & $1 \cdot 7^{a}$ & $0 \cdot 1$ \\
\hline TBARS $(\mu \mathrm{M})$ & $6 \cdot 0^{\mathrm{b}}$ & 0.2 & $5 \cdot 1^{\mathrm{a}}$ & 0.3 & $5 \cdot 1^{\mathrm{a}}$ & 0.2 & $27 \cdot 0^{a}$ & $2 \cdot 0$ & $22.0^{\mathrm{b}}$ & $2 \cdot 0$ & $23 \cdot 0^{a}$ & $3 \cdot 0$ \\
\hline $\mathrm{NO}(\mu \mathrm{M})$ & $21 \cdot 0^{a}$ & $2 \cdot 0$ & $26 \cdot 0^{\mathrm{b}}$ & $2 \cdot 0$ & $28 \cdot 0^{\mathrm{b}}$ & $2 \cdot 0$ & $104 \cdot 0^{\mathrm{a}}$ & $7 \cdot 0$ & $144 \cdot 0^{\mathrm{b}}$ & $5 \cdot 0$ & $155 \cdot 0^{\mathrm{b}}$ & $12 \cdot 0$ \\
\hline
\end{tabular}

DRW, dealcoholized red wine; DWW, dealcoholized white wine; ORAC, oxygen radical absorbance capacity; TBARS, thiobarbituric acid-reactive substances.

a,b,c Mean values for plasma or supernatant fraction of exudates with unlike superscript letters were significantly different $(P<0.05)$.

${ }^{*}$ For details of diets and procedures, see Table 1 and Materials and methods.

concentration decreased by $42 \%$ ) in plasma, and the reducing power $(41 \%)$, ORAC $(93 \%)$ and $\mathrm{O}_{2}^{--}$scavenging activity (50\% scavenging concentration decreased by $27 \%$ ) in exudate supernatant fractions. Feeding rats a DWW-rich diet increased the reducing power and $\mathrm{O}_{2}^{--}$-scavenging activities in plasma (32 and $13 \%$, respectively) and in supernatant fractions of exudates (41 and $24 \%$, respectively) and the ORAC (23\%) in plasma. Dietary administration of dealcoholized wines 
Table 6. Superoxide anion $\left(\mathrm{O}_{2}^{--}\right)$and nitric oxide production by polymorphonuclear cells* (Mean values with their standard errors for two replicates from seven rats)

\begin{tabular}{|c|c|c|c|c|c|c|}
\hline & \multicolumn{2}{|c|}{ Control } & \multicolumn{2}{|c|}{ DRW } & \multicolumn{2}{|c|}{ DWW } \\
\hline & Mean & SE & Mean & SE & Mean & SE \\
\hline $\mathrm{O}_{2}^{--}$production $\left(\mathrm{nmol} / 10^{6}\right.$ cells per $\mathrm{h}$ ) & $4.45^{\mathrm{b}}$ & 0.49 & $1.95^{\mathrm{a}}$ & 0.32 & $2 \cdot 51^{\mathrm{a}}$ & $0.39^{\mathrm{a}}$ \\
\hline NO production (nmol/106 cells per $h$ ) & $0.91^{\mathrm{a}}$ & $0.29^{a}$ & $3.17^{b}$ & 0.35 & $2.95^{\mathrm{b}}$ & 0.30 \\
\hline
\end{tabular}

DRW, dealcoholized red wine; DWW, dealcoholized white wine

a,b Mean values within a row with unlike superscript letters were significantly different $(P<0.05)$.

${ }^{*}$ For details of diets and procedures, see Table 1 and Materials and methods.

significantly decreased thiobarbituric acid-reactive substances in plasma from both groups of dealcoholized wine-fed rats and in the supernatant fraction of exudates from DRW-fed rats (Table 5). Values in exudate supernatant fractions were about $4 \cdot 5$-fold higher than in plasma $(6 \cdot 0 \mu \mathrm{M}$ in plasma of control rats).

NO concentration was about 5 -fold higher in the supernatant fraction of exudates than in plasma, and significantly greater in dealcoholized wine-fed rats (Table 5). The NO levels in exudate supernatant fractions, which are indicative of NO production by inflammatory cells in situ, are consistent with the ratios of free citrulline $v$. free arginine found in this compartment (0.76(SE 0.08), 1.08 (SE 0.12) and 1.34 (SE 0.12 ) for control, DRW and DWW, respectively), which is equivalent to increases of 43 and $77 \%$ in DRW- and DWWtreated rats, respectively, as compared with rats fed the control diet. No correlation between NO and number of cells in exudates was observed. However, a positive correlation between $\mathrm{NO}$ and citrulline:arginine in the supernatant fraction of exudates was detected ( $r 0.5304 ; P=0.0235)$.

Free radical production by polymorphonuclear leucocytes and inducible nitric oxide synthase and cyclo-oxygenase-2 assays

The ex vivo $\mathrm{O}_{2}^{--}$production by PMN leucocytes isolated from the inflammatory exudates decreased by $56 \%$ in DRW- and by $44 \%$ in DWW-treated rats (Table 6), while NO generation increased by 220 and $200 \%$ in DRW- and DWW-fed rats, respectively (Table 6).

iNOS protein expression increased by 47 and $28 \%$ in DRW- and DWW-fed rats, respectively (Fig. 1 (a) and 1 (b)). However, iNOS activity was more enhanced by the administration of dietary wines (67 and $75 \%$ for DRW and DWW, respectively) than was its expression (Fig. 1 (b)).

COX-2 expression (Fig. 2 (a) and 2 (b)) and activity (Fig. 2 (b)) significantly increased only in rats fed the DRW-rich diet (36 and $30 \%$, respectively).

\section{Discussion}

Polyphenols are important non-alcoholic antioxidant compounds in wine. Most studies on their biological activities have focused on the prevention of atherosclerosis or on the effect on macrophages and platelets, and few studies have been performed using PMN leucocytes as cells present in an acute inflammatory stage. The present paper demonstrates that the administration of DRW- and DWW-rich diets to rats modulates the oxidative stress and the inflammatory response in the carrageenan-induced granuloma pouch, used as a model of acute inflammation.

It has been assumed that red wine shows more protective effects than white wine in vitro because of its high content of polyphenolic antioxidants. Moreover, wine also contains non-polyphenolic compounds with antioxidant activity, such as ascorbic acid and sulfites ${ }^{27}$. These two compounds were present at similar concentrations in DRW and DWW and, thus, the differences observed in the antioxidant activities of these wines should be attributed to their qualitative and quantitative differences in polyphenols. However, the similarities in plasma and supernatant fraction of inflammatory exudates from the two treated groups support the view that the bioavailable polyphenols ${ }^{8-10}$ and some non-polyphenolic compounds such as ascorbic acid and sulfites can be responsible for the low oxidative stress observed in vivo. We can rule out the contribution of uric acid generated from fructose in vivo ${ }^{28}$ as its concentration in white wine was lower than in red wine, and also because rats have uricase. Small differences
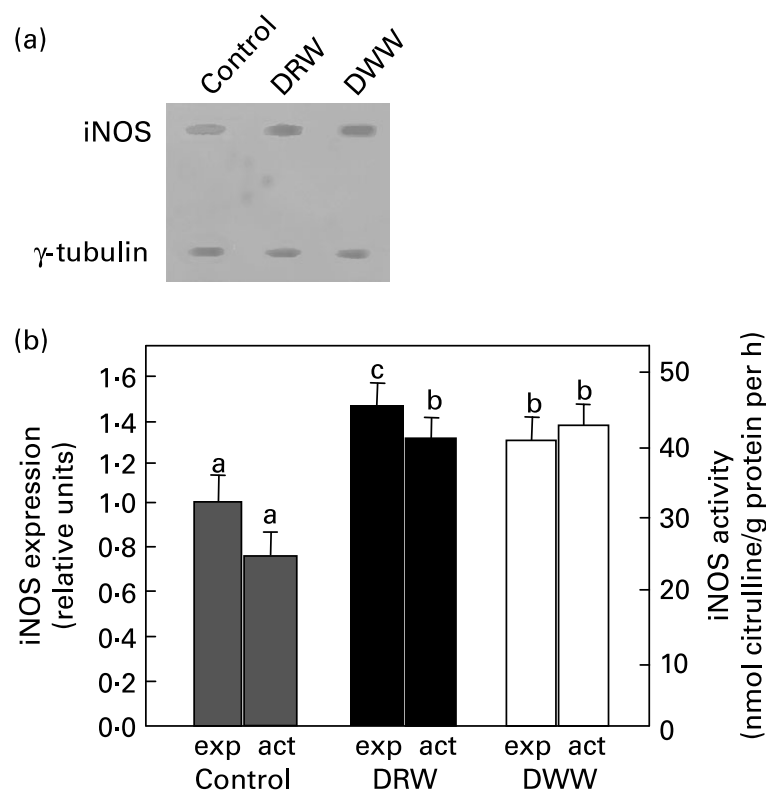

Fig. 1. Inducible NO synthase (iNOS) protein. (a) Representative iNOS expression by Western blot. (b) iNOS expression (exp) and activity (act) in polymorphonuclear cells from the inflammatory exudate of rats fed a control diet, or diets supplemented with dealcoholized red wine (DRW) or dealcoholized white wine (DWW) for $15 \mathrm{~d}$. Values are means with their standard errors represented by vertical bars (two replicates from four rats). ${ }^{a, b, c}$ Mean values for exp or act with unlike letters were significantly different $(P<0.05)$. 


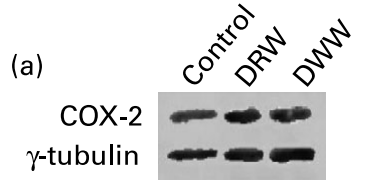

(b)

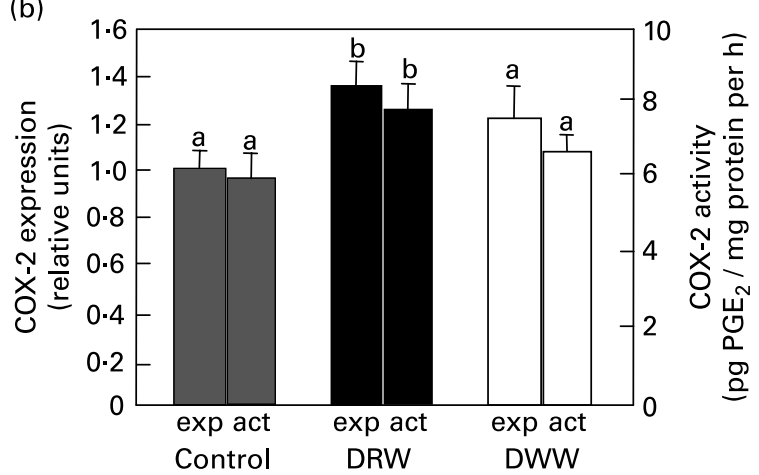

Fig. 2. Cyclo-oxygenase (COX)-2 protein. (a) Representative COX-2 expression by Western blot. (b) COX-2 expression (exp) and activity (act) in polymorphonuclear cells from the inflammatory exudate of rats fed a control diet, or diets supplemented with dealcoholized red wine (DRW) or dealcoholized white wine (DWW). Values are means with their standard errors represented by vertical bars (two replicates from four rats). ${ }^{a, b}$ Mean values for exp or act with unlike letters were significantly different $(P<0.05)$.

in plasma concentration of polyphenols in subjects given red and white wine for $15 \mathrm{~d}$ were also observed by Pignatelli et $a .^{29}$ while the total polyphenolic content of red wine was approximately 7-fold higher.

The effect of DRW and DWW dietary administration on oxidative stress associated with an inflammatory process has also been tested in the present study in PMN cells isolated from inflammatory exudates. When activated, PMN cells release $\mathrm{O}_{2}^{--}$(generated by NADPH oxidase and xanthine oxidase) and $\mathrm{NO}$ (generated by iNOS). $\mathrm{O}_{2}^{--}$has been associated with tissue damage ${ }^{30}$ and NO is recognized to be either a protective or a harmful agent ${ }^{31}$ depending on the amount produced, the site of production and the presence of other reactive species $^{32}$. In this sense, $\mathrm{NO}$ is a good target for $\mathrm{O}_{2}^{--}$-yielding peroxynitrite $^{12,13}$. Its generation should be deleterious unless an excess of NO remains acting as a protective agent. This latter possibility is confirmed by the high levels of NO in the supernatant fraction of exudates from treated rats and the subsequent decrease in cell number. However, when we studied the ex vivo activation of PMN cells in the presence of $\mathrm{N}$-imino-ethyl-L-ornithine or superoxide dismutase in the incubation medium, we were able to measure the $\mathrm{O}_{2}^{--}$or $\mathrm{NO}$, respectively, in the absence of peroxynitrite generation. In this situation, the two dealcoholized wines had similar effects on both parameters. The decrease in $\mathrm{PMN} \mathrm{O}_{2}^{--}$release observed ex vivo can be linked to a down regulation of NADPH oxidase by NO, as observed in the same model of inflammation ${ }^{11}$. The increase in NO is consistent both with the NO concentration and citrulline:arginine in the supernatant fraction of exudates, which are the result of the in situ production of NO by PMN cells recruited into the granuloma pouch, as well as with their iNOS expression and activity. It is difficult to consider polyphenols as only responsible for the increase in NO release. Sharma et al. ${ }^{33}$ observed that ascorbate regulates NO generation by PMN cells by stabilization of tetrahydrobiopterin, which is a cofactor for iNOS activation. Although we cannot rule out the contribution of ascorbate in iNOS activation, the similar increases in iNOS expression induced by DRW and DWW support the involvement of polyphenols in NO generation. Regarding the similar effects of wines observed in the present paper we have to notice that Whelan et $a{ }^{34}{ }^{34}$ showed that impaired endothelial function in coronary arterial disease was improved after the ingestion of white and red wine. The decrease in $\mathrm{O}_{2}^{--}$generation and the increase in NO by PMN cells and the high levels of NO in the supernatant fraction of the exudates explain the low levels of oxidative stress in plasma and supernatant fraction of the exudates.

Neutrophil migration during an inflammatory response is the result of adhesion on endothelial cells followed by transmigration to the extravascular space and is influenced by a variety of factors, including $\mathrm{O}_{2}^{--}$and $\mathrm{NO} . \mathrm{O}_{2}^{--}$favours the sequestration of leucocytes ${ }^{14}$ whereas NO produced by endothelial NOS or by leucocyte-derived iNOS prevents leucocyte recruitment $^{35-37}$. The similar low number of cells in the exudates can be explained by the similar decrease in $\mathrm{O}_{2}^{-}$and similar increase in NO by PMN cells after the administration of DRW- and DWW-rich diets. Moreover, neutrophil apoptosis induced by NO may also be involved ${ }^{37}$.

In our model of inflammation both $\mathrm{O}_{2}^{--}$and $\mathrm{NO}$ are generated by activated PMN cells. Up regulation of COX-2 is a key event in inflammation and its relationship to NO is controver$\operatorname{sial}^{38,39}$. The increase in COX-2 expression and activity in $\mathrm{PMN}$ cells and the increase in $\mathrm{PGE}_{2}$ levels in the supernatant fraction of exudates observed in DRW-treated rats, but not in DWW-treated rats, indicate that under our conditions NO is not critical for COX-2 activation. The paper by Fujimoto et al. ${ }^{39}$ suggests that $\mathrm{PGE}_{2}$ production is complex and that $\mathrm{H}_{2} \mathrm{O}_{2}$, NO and peroxynitrite can have different modulatory effects on $\mathrm{COX}$ activities depending on their concentration in cells. The inhibitory effect of polyphenols on COX observed in vitro ${ }^{7}$ is not observed in vivo in the present study and this can be attributed to their metabolism or bioavailability. In this model of acute inflammation, the up regulation of COX-2 could indicate that the DRW was proinflammatory. However, the decreased PMN cell number and oxidative stress, the increased NO concentration in supernatant fraction of exudates and the decreased capability of PMN cells to generate $\mathrm{O}_{2}^{--}$and the increased $\mathrm{NO}$ production can all be considered as anti-inflammatory effects of both DRW- and DWW-rich diets.

During the past decade, we have come to appreciate the prominent role played by inflammation and oxidative stress in several diseases. Our observations indicate that the non-alcoholic compounds of red and white wines are similarly effective in vivo. By decreasing $\mathrm{O}_{2}^{--}$production and increasing NO production they control cell infiltration and prevent physiopathological processes associated with inflammation. Moreover, NO, by its antioxidant activity, will terminate the lipid radical chain reaction ${ }^{40,41}$. It is thus likely that the antioxidant and anti-inflammatory effects of DRW and DWW in vivo can be mainly attributed to polyphenols, although further research is required to elucidate the responsible metabolites. 


\section{Acknowledgements}

The present study was supported by the Spanish Ministry of Science and Technology (grant VIN00-041) and the Generalitat de Catalunya (grant 2001SGR00134). We thank Robin Rycroft for English language revision and the University of Barcelona for the scientific and technical services and for providing D. L. with support.

\section{References}

1. Rice-Evans CA, Miller NJ \& Paganga G (1996) Structure-antioxidant activity relationships of flavonoids and phenolic acids. Free Radic Biol Med 20, 933-956.

2. Lotito SB \& Fraga CG (1998) (+)-Catechin prevents human plasma oxidation. Free Radic Biol Med 24, 435-441.

3. Robak J \& Gryglewski RJ (1988) Flavonoids are scavengers of superoxide anions. Biochem Pharmacol 37, 837-841.

4. Paquay JB, Haenen GR, Stender G, Wiseman SA, Tijburg LB \& Bast A (2000) Protection against nitric oxide toxicity by tea. $J$ Agric Food Chem 48, 5768-5772.

5. Lindahl M \& Tagesson C (1997) Flavonoids as phospholipase A2 inhibitors: importance of their structure for selective inhibition of group II phospholipase A2. Inflammation 21, 347-356.

6. Morikawa K, Nonaka M, Narahara M, Torii I, Kawaguchi K, Yoshikawa T, Kumazawa Y \& Morikawa S (2003) Inhibitory effect of quercetin on carrageenan-induced inflammation in rats. Life Sci 74, 709-721.

7. Laughton MJ, Evans PJ, Moroney MA, Hoult JR \& Halliwell B (1991) Inhibition of mammalian 5-lipoxygenase and cyclo-oxygenase by flavonoids and phenolic dietary additives. Relationship to antioxidant activity and to iron ion-reducing ability. Biochem Pharmacol 42, 1673-1681.

8. Scalbert A \& Williamson G (2000) Dietary intake and bioavailability of polyphenols. J Nutr 130, Suppl. 8S, 2073S-2085S.

9. Benito S, Buxaderas S \& Mitjavila MT (2004) Flavonoid metabolites and susceptibility of rat lipoproteins to oxidation. Am J Physiol Heart Circ Physiol 287, H2819-H2824.

10. Manach C, Scalbert A, Morand C, Remesy S \& Jimenez L (2004) Polyphenols: food sources and bioavailabity. Am J Clin Nutr 79, 727-747.

11. Rodenas J, Mitjavila MT \& Carbonell T (1998) Nitric oxide inhibits superoxide production by inflammatory polymorphonuclear leukocytes. Am J Physiol Heart Circ Physiol 274, C827-C830.

12. Huie RE \& Padmaja S (1993) The reaction of NO with superoxide. Free Radic Res Comms 18, 195-199.

13. Rodenas J, Carbonell T \& Mitjavila MT (2000) Different roles for nitrogen monoxide and peroxynitrite in lipid peroxidation induced by activated neutrophils. Free Radic Biol Med 28, $374-380$

14. Shigematsu S, Ishida S, Hara M, Takahashi N, Yoshimatsu H, Sakata T \& Korthuis RJ (2003) Resveratrol, a red wine constituent polyphenol, prevents superoxide-dependent inflammatory responses induced by ischemia/reperfusion, platelet-activating factor, or oxidants. Free Radic Biol Med 34, 810-817.

15. Meagher EA (1999) Alcohol-induced generation of lipid peroxidation products in humans. J Clin Invest 104, 805-813.

16. Benito S, Lopez D, Saiz MP, Buxaderas S, Sanchez J, Puig-zParellada P \& Mitjavila MT (2002) A flavonoid-rich diet increases nitric oxide production in rat aorta. $\mathrm{Br} J$ Pharmacol 135, 910-916.

17. Hubmann B, Monnier D \& Roth M (1969) A rapid, accurate determination of ascorbic acid; application to the measurement of plasma levels. Clin Chim Acta 25, 161-166.
18. Flamini R (2003) Mass spectrometry in grape and wine chemistry. Part I: Polyphenols. Mass Spectrom Rev 22, 218-250.

19. Singleton VL \& Rossi JA (1965) Colorimetric of total phenols with phosphomolybdic phosphotungstic acid reagents. Am J Enol Viticult 16, 144-158.

20. Oyaizu M (1986) Studies on products of browning reaction prepared from glucosamine. Jpn J Nutr 44, 307-315.

21. Glazer AN (1990) Phycoerythrin fluorescence-based assay for reactive oxygen species. Methods Enzymol 186, 161-168.

22. Ukeda H, Maeda S, Ishii T \& Sawamura M (1997) Spectrophotometric assay for superoxide dismutase based on tetrazolium salt 3'-1-(phenylamino)-carbonyl-3, 4-tetrazolium]bis(4-methoxy-6-nitro)benzenesulfonic acid hydrate reduction by xanthine-xanthine oxidase. Anal Biochem 251, 206-209.

23. Vriesman MF, Haenen GR, Westerveld GJ, Paquay JB, Voss HP \& Bast A (1997) A method for measuring nitric oxide radical scavenging activity. Scavenging properties of sulfur-containing compounds. Pharm World Sci 19, 283-286.

24. Muntane J, Fritsch P, Carbonell T, Saiz MP, Puig-Parellada P \& Mitjavila MT (1991) Modulation of exudate inflammation parameters in rat carrageenan-induced granuloma by modification of exudate iron levels. Agents Actions 32, 167-172.

25. Yagi K (1984) Assay for blood plasma or serum. Methods Enzymol 105, 328-331.

26. Moore S, Spackman DH \& Stein WH (1958) Automatic recording apparatus for use in the chromatography of amino acids. Fed Proc 17, 1107-1115.

27. Mitsuhashi H, Ikeuchi H \& Nojima Y (2001) Is sulfite an antiatherogenic compound in wine? Clin Chem 47, 1872-1873.

28. Lotito SB \& Frei B (2004) The increase in human plasma antioxidant activity after apple consumption is due to the metabolic effect of fructose on urate, not apple-derived antioxidant flavonoids. Free Rad Biol Med 37, 251-258.

29. Pignatelli P, Ghiselli A, Buchetti B, Carnevale R, Natella F, Germano G, Fimognari F, Di Santo S, Lenti L \& Violi F (2006) Polyphenols synergistically inhibit oxidative stress in subjects given red and white wine. Atherosclerosis 188, $77-83$.

30. Vega VL, Maldonado M, Maradones L, Manriquez V, Vivaldi E, Roa J \& Ward PH (1998) Inhibition of nitric oxide synthesis aggravates hepatic oxidative stress and enhances superoxide dismutase inactivation in rats subjected to tourniquet shock. Shock 9, 320-328.

31. Ialenti A, Moncada S \& Di RM (1993) Modulation of adjuvant arthritis by endogenous nitric oxide. Br J Pharmacol 110, 701-706.

32. Paul-Clark MJ, Gilroy DW, Willis D, Willoughby DA \& Tomlinson A (2001) Nitric oxide synthase inhibitors have opposite effects on acute inflammation depending on their route of administration. J Immunol 166, 1169-1177.

33. Sharma P, Raghavan SAV \& Dikshit M (2003) Role of ascorbate in the upregulation of nitric generation by polymorphonuclear leukocytes. Biochem Biophys Res 309, 12-17.

34. Whelan AP, Sutherland WHF, McCormick MP, Yeoman DJ, de Jong SA \& Williams MJA (2004) Effects of white and red wine on endothelial function in subjects with coronary artery disease. Int Med J 34, 224-228.

35. Binion DG, Fu S, Ramanujam KS, Chai YC, Dweik RA, Drazba JA, Wade JG, Ziats NP, Erzurum SC \& Wilson KT (1998) iNOS expression in human intestinal microvascular endothelial cells inhibits leukocyte adhesion. Am J Physiol Gastrointest Liver Physiol 275, G592-G603.

36. Hickey MJ (2001) Role of inducible nitric oxide synthase in the regulation of leucocyte recruitment. Clin Sci (Lond) 100, $1-12$.

37. Secco DD, Paron JA, de Oliveira SH, Ferreira SH, Silva JS \& Cunha Fde Q (2004) Neutrophil migration in inflammation: 
nitric oxide inhibits rolling, adhesion and induces apoptosis. Nitric Oxide 9, 153-164.

38. Salvemini D, Misko TP, Masferrer JL, Seibert K, Currie MG \& Needleman P (1993) Nitric oxide activates cyclooxygenase enzymes. Proc Nat Acad Sci USA 90, 7240-7244.

39. Fujimoto Y, Uno E \& Sakuma S (2004) Effects of reactive oxygen and nitrogen species on cyclooxygenase-1 and -2 activities. Prostaglandins Leukot Essent Fatty Acids 71, 335-340.
40. Rubbo H (1994) Nitric oxide regulation of superoxide and peroxinitrite-dependent lipid peroxidation. J Biol Chem 269, $26066-26075$.

41. Rubbo H, Radi R, Anselmi D, Kirk M, Barnes S, Butler J, Eiserich JP \& Freeman BA (2000) Nitric oxide reaction with lipid peroxyl radicals spares $\alpha$-tocopherol during lipid peroxidation. Greater oxidant protection from the pair nitric oxide/ $\alpha$-tocopherol than $\alpha$-tocopherol/ascorbate. J Biol Chem 275, 10812-10818 